\title{
The Novel Combination of Theophylline and Bambuterol as a Potential Treatment of Hypoxemia in Humans
}

\begin{tabular}{|c|c|}
\hline Journal: & Canadian Journal of Physiology and Pharmacology \\
\hline Manuscript ID & cjpp-2016-0635.R1 \\
\hline Manuscript Type: & Article \\
\hline Date Submitted by the Author: & 22-Feb-2017 \\
\hline Complete List of Authors: & $\begin{array}{l}\text { Strand, Trond-Eirik; Norwegian Armed Forces Medical Services, Institute of } \\
\text { Aviation Medicine } \\
\text { Khiabani-Zare, Hasse; Oslo universitetssykehus Rikshospitalet, Department } \\
\text { of Pharmacology } \\
\text { Boico, Alina; Duke University School of Medicine, Department of Radiation } \\
\text { Oncology } \\
\text { Radiloff, Daniel; Taconic Biosciences Inc } \\
\text { Zhao, Yulin; Duke University Hospital, Radiation Oncology } \\
\text { Hamilton, Karyn; Colorado State University, Department of Health and } \\
\text { Exercise Sciences } \\
\text { Christians, Uwe; University of Colorado Denver School of Medicine, } \\
\text { Department of Medicine } \\
\text { Klawitter, Jelena; University of Colorado Denver School of Medicine } \\
\text { Noveck, Robert; Duke University School of Medicine, Department of } \\
\text { Medicine } \\
\text { Piantadosi, Claude; Duke University School of Medicine, Hyperbaric Center } \\
\text { Bell, Christopher; Colorado State University, Department of Exercise } \\
\text { Sciences } \\
\text { Irwin, David; University of Colorado Denver School of Medicine, } \\
\text { Department of Medicine } \\
\text { Schroeder, Thies; Johannes Gutenberg Universitat Mainz, Department of } \\
\text { Biochemistry }\end{array}$ \\
\hline Keyword: & $\begin{array}{l}\text { Hypoxia, Combination therapy, Xanthine drugs, Beta adrenergic receptor } \\
\text { agonist, Hypoxemia }\end{array}$ \\
\hline
\end{tabular}




\section{The Novel Combination of Theophylline and Bambuterol as a Potential Treatment of Hypoxemia in Humans}

Trond-Eirik Strand (M.D., Ph.D.) ${ }^{1}$, Hasse Z Khiabani (M.D., Ph.D.) ${ }^{2}$, Alina Boico (B.S.) ${ }^{3}$, Daniel Radiloff (Ph.D.) ${ }^{4}$, Yulin Zhao (M.D.) ${ }^{3}$, Karyn L. Hamilton (Ph.D.) $)^{5}$, Uwe Christians (Ph.D. $)^{6}$, Jelena Klawitter (Ph.D.) ${ }^{6}$, Robert J. Noveck (M.D., Ph.D.) ${ }^{7}$, Claude A. Piantadosi (M.D.) ${ }^{8}$, Christopher Bell (Ph.D.) $)^{5}$, David Irwin (Ph.D.) ${ }^{9}$, Thies Schroeder (Ph.D.) $)^{9,10}$

1. Norwegian Armed Forces Medical Services, Institute of Aviation Medicine, Oslo, Norway

2. Department of Pharmacology, Oslo University Hospital, Rikshospitalet, Oslo, Norway

3. Department of Radiation Oncology, Duke University Medical Center, Durham NC, USA

4. Taconic Biosciences, Hudson NY, USA

5. Department of Health and Exercise Science, Colorado State University, Fort Collins CO, USA

6. iC42 Integrated Solutions in Clinical Research and Development, University of Colorado Denver, Anschutz Medical Campus, Aurora CO, USA

7. Department of Medicine, Duke University Medical Center, Durham NC, USA

8. Hyperbaric Center, Duke University Medical Center, Durham NC, USA

9. Department of Medicine, University of Colorado Denver, Anschutz Medical Campus, Aurora CO, USA

10. Department of Biochemistry and Pharmacology, University of Mainz, Germany

To whom communication should be directed:

Thies Schroeder, PhD

Department of Biochemistry

University of Mainz

Jakob Welder-Weg 11

55128 Mainz, Germany

Phone 1: $+49+613139-22967$

Phone 2: $+49+613139-24853$

Fax: $+49613139-26747$

Email: thschroe@uni.mainz.de

Short running title: Drug combination to alleviate hypoxemia 


\section{Abstract}

Hypoxemia can be life-threatening both, acutely and chronically. Because hypoxemia causes vascular dysregulation that further restricts oxygen availability to tissue, it can be pharmacologically addressed. We hypothesized that theophylline can be safely combined with the $\beta 2$ adrenergic vasodilator bambuterol to improve oxygen availability in hypoxemic patients. Ergogenicity and hemodynamic effects of bambuterol and theophylline were measured in rats under hypobaric and normobaric hypoxia $\left(12 \% \mathrm{O}_{2}\right)$. Feasibility in humans was assessed using randomized, double-blind testing of the influence of combined slow-release theophylline $(300 \mathrm{mg})$ and bambuterol $(20 \mathrm{mg})$ on adverse events (AEs), plasma $\mathrm{K}^{+}$, pulse, blood pressure, and drug interaction. Both drugs and their combination significantly improved hypoxic endurance in rats. In humans, common AEs were low $\mathrm{K}^{+}$ (<3.5mmol/L, bambuterol: 12 , theophylline: 4 , combination: 13 episodes) and tremors $(10,0,14$ episodes). No exacerbation or SAE occurred when drugs were combined. A drop in plasma $\mathrm{K}^{+}$ coincided with peak bambuterol plasma concentrations. Bambuterol increased heart rate by approx. $13 \mathrm{bpm}$. Drug interaction was present but small. We report promise, feasibility and relative safety of combined theophylline and bambuterol as a treatment of hypoxemia in humans. Cardiac safety and blood $\mathrm{K}^{+}$will be important safety endpoints when testing these drugs in hypoxemic subjects.

Key words: Hypoxemia, hypoxia, combination therapy, xanthine drugs, beta adrenergic receptor agonist, drug safety, bioequivalence, human study, animal study

Clinical trials: This study contains results from a human clinical trial. The description of the trial lists under the following URL: https://clinicaltrials.gov/ct2/show/NCT01566565 


\section{Introduction}

Lack of oxygen in the blood, hypoxemia, can be caused by various conditions, such as environmental shortage of oxygen ("thin air" at high altitude), obstruction of air flow (chronic obstructive pulmonary disease, pneumonia, pulmonary fibrosis), inefficient oxygen loading of the blood (anatomic shunting, anemia) and central nervous dysregulation (anesthesia, central sleep apnea). While severe hypoxemia $\left(<75 \% \mathrm{SaO}_{2}\right)$ requires immediate intervention, moderate hypoxemia (75-89\%) leads, in the short term, to decreased physical endurance. However, long-term consequences of chronic hypoxemia can be much more serious, involving digital clubbing, progressive pulmonary remodeling and pulmonary arterial hypertension (PAH), and right ventricular failure (Kim et al. 2015; Nakamura et al. 2002; H. Zhang et al. 2015). Hypoxemia is usually treated with supplemental oxygen (Fromm et al. 1994), however, when oxygen supplementation is insufficient or difficult to achieve, such as during severe $\mathrm{PAH}$ or at high altitude, a pharmacological relief of hypoxemia would be a useful alternative.

Hypoxemia can be pharmacologically targeted by inhibiting its downstream dysregulation that further reduces oxygen availability to tissue: for example, hypoxemia triggers the release of the vasoconstrictive protein hormone endothelin-1, which contributes to reduced uptake of oxygen by causing ventilation-perfusion mismatching in the lung (Kylhammar and Rådegran 2017). Endothelin-1 can also lead to vasoconstriction of terminal elements of the arterial tree, thus negatively affecting capillary blood flow in the terminal circulation and further reducing transport and availability of oxygen to tissue (Barrett-O'Keefe et al. 2013; Borysova et al. 2013; Hall et al. 2014; Murray et al. 2016; Neuhaus et al. 2016). Consequently, anti-vasoconstrictive therapy with endothelin-1 blockade demonstrates efficacy to relieve oxygen shortage to tissue by inhibiting these known dysregulations (Kawano et al. 2007; Naeije et al. 2010; Pitsiou et al. 2009). Since additional factors, such as prostaglandins and adenosine, are involved in hypoxemic dysregulation of tissue hemodynamics, combination treatment might be more effective than monotherapy in improving the supply of oxygen to tissue during hypoxemia (Dayan et al. 2016; Dubrey et al. 2016; Gouyon et al. 1988). We 
recently demonstrated that the combination of the xanthine drug theophylline and an endothelinblocking vasodilator improves exercise performance capacity of hypoxemic rats (Radiloff et al. 2012). This treatment, which we have recently tested for safety in humans (ClinicalTrials.gov, NCT01530464 and NCT01794078), has the advantage that it does not rely on increasing $\mathrm{SaO}_{2}$, but rather accelerates the rate of oxygen transport to the skeletal muscle. However, not all hypoxemic patients respond equally well to endothelin receptor antagonism (Jain et al. 2017) and thus, alternative treatment options would be useful. Because $\beta$-adrenergic receptors are also strongly involved in pulmonary and peripheral blood flow regulation (Blauw et al. 1995; Leblais et al. 2008; Nagai et al. 2014), we hypothesize that the combination of theophylline with a $\beta$-adrenergic receptor agonist has also beneficial effects. We further hypothesize that this combination is, in principle, feasible in humans. To test this hypothesis, we have chosen the long-acting $\beta$-agonist bambuterol as a combination partner for theophylline, which is orally available and has a plasma half-life comparable to theophylline.

\section{Methods}

Measurement of exercise capacity of theophylline- and bambuterol-treated rats under hypobaric hypoxia

These animal procedures were pre-approved by Duke University Institutional Animal Care and Use Committee (DUIACUC) and were carried out in accordance with the Guide for the Care and Use of Laboratory Animals (1996, published by National Academy Press, 2101 Constitution Ave. NW, Washington, DC 20055, USA). Bambuterol and theophylline were administered intraperitoneally (IP). Theophylline was dosed at $15 \mathrm{mg} / \mathrm{kg}$ and bambuterol at either $0.05 \mathrm{mg} / \mathrm{kg}$ (high dose) or $0.01 \mathrm{mg} / \mathrm{kg}$ (low dose). Only the low dose was tested in combination with theophylline. Female Sprague Dawley rats were consistently used for all exercise experiments as reported (Radiloff et al. 2012). Procedures to measure exercise performance capacity at simulated high altitude in rats have also been published (Radiloff et al. 2012). In brief, rats were habituated to running in motorized wheels (Figure 1A, 
Lafayette Instruments, Lafayette, IN) at a slow pace for approximately 10 days, to teach them to run in a motorized wheel while avoiding physical training effects. On days of drug efficacy testing, the animals were injected i.p. with the study drug or control treatment and then transferred to individual running wheels inside a hypobaric chamber accompanied by an investigator (Figure 1A). The air was then evacuated from the chamber until an atmospheric equivalent of 4,267 m (approx. $0.6 \mathrm{~atm}$ ) was reached. Wheel motion was started 30 minutes post injection of the study drugs, at 3 meters per minute, was then increased to $9 \mathrm{~m} / \mathrm{min}$, and finally to $12 \mathrm{~m} / \mathrm{min}$ (Figure 1B). Signs of exhaustion caused the removal of individual animals from the wheel, followed by a short test to confirm fatigue (Radiloff et al. 2012). After the run, all animals were returned to sea level and euthanized using $\mathrm{CO}_{2}$, as determined by the protocol.

Hemodynamic studies in awake, theophylline- and bambuterol-treated rats in normoxia and hypoxia

In order to address safety concerns ahead of combining theophylline and bambuterol in hypoxemic humans, we have employed a rat model to monitor mean arterial pressures, heart rates, and plasma concentrations of $\mathrm{K}^{+}$. These animal procedures were pre-approved by the UC Denver Institutional Animal Care and Use Committee (IACUC) and were carried out in accordance with the Guide for the Care and Use of Laboratory Animals (1996, published by National Academy Press, 2101 Constitution Ave. NW, Washington, DC 20055, USA). An awake hypoxic rat model was used to study changes in hemodynamics and blood chemistry, as described previously (Irwin et al. 2008). Briefly, male Sprague Dawley rats of 280-350 g were anesthetized and equipped with chronic indwelling catheters into the carotid and pulmonary artery, and vena cava for hemodynamic and cardiac output measurements. Treatments were administered through the jugular catheter. Rats were randomized into four treatment groups (vehicle, theophylline, bambuterol and the combination of theophylline and bambuterol) and placed into a gas-controlled Plexiglas chamber with a portal for catheter access. Breathing gas was normal $\left(21 \% \mathrm{O}_{2}\right)$ and hypoxic air $\left(12 \% \mathrm{O}_{2}\right.$, Figure $\left.1 \mathrm{C}\right)$. Blood pressures and heart 
rates were measured through pressure transducers, and blood chemistries were measured from samples collected from arterial and venous catheters, as described previously (Irwin et al. 2008).

\section{Criteria for human study participation}

Candidates were recruited in Oslo, Norway, and the human study was conducted at the Oslo University Hospital, Rikshospitalet. Healthy, non-smoking adults between 18 and 40 years old (both genders) were eligible for study participation if they were willing to fast 8 hours prior to screening, abstain from alcohol or xanthine-containing food or beverages for at least 48 hours before admission to meeting all of the inclusion and none of the exclusion criteria, which are listed in Supplementary Table 1.

\section{Clinical study design}

This was an open-label, two-sequence, three-period, randomized crossover study. Study subjects ( $n=20$ at study start, 3 withdrew during the study) were randomized into one of two sequences to receive either a single dose of theophylline slow release (Theo-Dur, $300 \mathrm{mg}$ ) or bambuterol (Bambec, $20 \mathrm{mg}$, period 1). After a washout time of 96 hours, dosing schedules were crossed over to receive the second study drug (period 2). After a second washout period of 96 hours, all subjects received both drugs concomitantly (period 3). Subjects were discharged following another washout of 96 hours (Figure 1D). The study was conducted in compliance with the Declaration of Helsinki and with international guidelines of Good Clinical Practice (GCP). All procedures were approved by the appropriate regulatory bodies, which include Norwegian Medicines Agency and local Ethics Committee. All study subjects gave informed written consent before commencement of study procedures.

\section{Pharmacokinetic evaluations}

Whole blood samples for analysis of drug metabolites and plasma $\mathrm{K}^{+}$concentrations were collected at the following time points: $0.5,1,2,3,4,5,6,8,10,12,24 \mathrm{hr}$ using a small indwelling venous catheter. Sodium heparin $(20-30 \mathrm{U} / \mathrm{ml})$ was used to maintain catheter patency prior to and/or during 
the collection periods. A 5-7 ml venous blood sample was collected at the specified times in prechilled polypropylene Vacutainer tubes containing sodium heparin for the preparation of plasma. The tube containing blood was gently inverted at about 6-8 times to ensure thorough mixing of anticoagulant with blood and placed into an ice-water bath until centrifuged. The samples were centrifuged at $1500 \mathrm{~g}$ for at least 10 minutes at $4^{\circ} \mathrm{C}$. Immediately after centrifugation, the plasma was separated into aliquots of at least 2-3 mL. All aliquoted samples for pharmacokinetics analysis were stored at $-80^{\circ} \mathrm{C}$ until shipment.

Theophylline was analyzed at the Department of Biochemistry, Oslo University Hospital, following the procedure outlined for the Cobas 8000 C502 analyzer (Roche/Hitachi). The analysis was based on the kinetic interaction of micro particles in solution (KIMS). Theophylline antibody is bound covalently to micro particles and drug derivatives are linked to a macromolecule. The kinetic interaction of micro particle in resolutions induced by the drug derivatives bind to the antibody on the micro particles and is inhibited by the presence of theophylline. There is a competitive reaction between the substance conjugate and theophylline to bind to theophylline antibody on micro particles. The subsequent kinetic interaction of micro particles is indirectly proportional to the amount of substance in the sample. The method was linear from $0.8-40.0 \mu \mathrm{g} / \mathrm{mL}(4.4-222 \mu \mathrm{mol} / \mathrm{L})$ for theophylline and the lower limit of quantification was $0.8 \mu \mathrm{g} / \mathrm{mL}$. Samples having higher drug concentrations were diluted with Preciset TDM I diluent $(0 \mu \mathrm{g} / \mathrm{mL})(1+1)$ and re-assayed. The lower detection limit representing the lowest measurable analyte level that could be distinguished from zero was calculated as the value lying two standard deviations above that of the $0 \mu \mathrm{g} / \mathrm{mL}$ calibrator (standard $1+2$ SD, repeatability, $n=21$ ).

After shipment of blood samples on dry ice, bambuterol and its active metabolite terbutaline were analyzed by iC42 Integrated Solutions in Clinical Research and Development (Aurora, CO, USA) using high-performance liquid chromatography- tandem mass spectrometry (LC-MS/MS). In brief, for quantification of bambuterol and terbutaline in EDTA plasma, $800 \mu \mathrm{L}$ methanol and $0.2 \mathrm{mmol} / \mathrm{L}$ ZnSO4 (70/30, v/v; protein precipitation solution) were added to $200 \mu \mathrm{L}$ sample. Terbutaline-d9 
(Toronto Research Chemicals (TRC), Toronto, Canada) was added as an internal standard to the protein precipitation solution. After centrifugation $\left(13,000 \mathrm{~g}, 10 \mathrm{~min}, 4^{\circ} \mathrm{C}\right), 50 \mu \mathrm{L}$ of the supernatant were injected onto the analytical column of the LC-MS/MS system (SB-C18, $250 \times 4.6 \mathrm{~mm}, 5 \mu \mathrm{m}$, Agilent Technologies, Santa Clara, CA). The HPLC mobile phases consisted of either $0.1 \%$ formic acid or methanol/acetonitrile $(1: 1, \mathrm{v} / \mathrm{v})$. Calibrators and quality control samples were run with each study sample batch. Calibration curves were linear with $r^{2}>0.99$, accuracy of the quality control samples was within $85-115 \%$ of the nominal concentrations and imprecision was $<15 \%$.

\section{Safety evaluation in the human trial}

Safety was determined by recording adverse events, laboratory endpoints (in particular plasma $\mathrm{K}^{+}$), and vital signs. $\mathrm{K}^{+}$was measured using an ABL 825 Flex blood gas analyser (Radiometer, Copenhagen, DK). All parameters were accredited for ISO 15189 and 22870 (POCT) by the Norwegian Accreditation authorities. Cardiac safety was assessed by comparing 12 -lead electrocardiograms collected at predose with those collected at 2, 4, and 12 hours post dose.

\section{Statistics}

Rats study: assessment of ergogenicity under hypobaric hypoxia

Individual endurance data for each animal was plotted using the Kaplan-Meyer method. Treatment effects were determined by comparison with the vehicle control using Log Rank Test and GraphPad Prism as statistics software. $P$ values of less than 0.05 were considered statistically significant.

Rat study: hemodynamic analysis in awake rat under normoxia and hypoxia

Differences in longitudinal parameters, i.e. between baseline, post drug injection, post hypoxia, and return to normoxia, were assessed using two-tailed, paired T-test. Analysis of variance (Kwon et al. 2015) was not used for this part of the analysis, to permit matched comparison if a parameter was missing. Cross-sectional differences between treatment groups were analyzed using ANOVA. Statistical software was GraphPad Prism (GraphPad Software, San Diego, CA, USA). 


\section{Human study: pharmacokinetic analysis}

The pharmacokinetics of both study drugs alone and in combination was estimated using a noncompartment model. Pharmacokinetics and bioequivalence analyses were carried out using the WinNonlin software (Phoenix, version 6.4., Pharsight/Certara, Princeton, NJ, USA).

The presence of pharmacokinetic drug-drug interactions was assessed using bioequivalence metrics as recommended by the 2012 FDA-CDER guidelines "Guidance for Industry. Drug Interaction Studies — Study Design, Data Analysis, Implications for Dosing, and Labeling Recommendations", whereas no pharmacokinetic drug-drug interaction is assumed if the $90 \%$ confidence intervals of the geometric mean test/reference ratios of $C_{\max }$ and $A \cup C_{0-T}$ fall entirely within the $80-125 \%$ equivalence limits. The bioequivalence analysis was based on In-transformed drug concentrations and included mixed effect model, sequence, period, and treatment as fixed effects and subject with sequence as a random effect.

Human study: power consideration for bioequivalence testing

The standard bioequivalence acceptance limits of $80-125 \%$ were used to demonstrate that exposure to the test drug (co-administration of bambuterol and theophylline) was bioequivalent to the reference drug (bambuterol or theophylline alone). The within-subject coefficient of variation (CV) was expected to be approximately $20 \%$ and the mean ratio was expected to be unity $\left(\mu_{\mathrm{GT}} / \mu_{\mathrm{RT}}=1.0\right)$. Although this study was a three-period design, sample size was estimated based on an AB/BA two period crossover design. For a type I error rate of $5 \%, 16$ subjects resulted in $>80 \%$ statistical power (Julious 2004).

Statistics: side-by-side comparisons between treatment parameters at all time points were carried out to investigate whether the drug combination would change vital signs, compared to the single drugs. This analysis was done from raw values, using ANOVA with correction for multiple comparisons. 
Human study: hemodynamic assessments

Significance in changes in hemodynamic parameters over time within a treatment group was assessed using paired ANOVA. Significant difference between treatment groups were analyzed using ANOVA on data that was normalized to the respective value at the time of dosing.

\section{Results}

Assessment of ergogenic effects of theophylline and bambuterol on hypoxic exercise performance of rats

Rats that were treated with bambuterol $(0.05 \mathrm{mg} / \mathrm{kg}$, i.p.) ran significantly longer under simulated high altitude at $4267 \mathrm{~m}$ than the control-treated group (Figure 2A). Treatment with theophylline (15 $\mathrm{mg} / \mathrm{kg}$, i.p.) also significantly increased exercise performance in hypoxic hypobaric rats (Figure 2B). When given at a lower dose $(0.01 \mathrm{mg} / \mathrm{kg})$, bambuterol in combination with theophylline $(15 \mathrm{mg} / \mathrm{kg})$ increased the time run to fatigue, whereas the single treatments did not (Figure $2 \mathrm{C}$ ). Animal numbers were 43-45 per treatment group in Figure $2 \mathrm{~A}-\mathrm{B}$, and 10 per group in Figure $2 \mathrm{C}$.

Pre-clinical safety assessment of combined theophylline and bambuterol in awake normoxic and hypoxic rats

Treatment with theophylline and bambuterol significantly decreased Mean Arterial Pressure (MAP) compared with control and combination: MAP dropped in all groups from an average of $132 \pm 13$ $\mathrm{mmHg}$ at baseline (1) to $129 \pm 13 \mathrm{mmHg}$ post injection (2), then to $114 \pm 14 \mathrm{mmHg}$ during hypoxia (3), and $126 \pm 12 \mathrm{mmHg}$ after return to normoxia (4) (Figure 2D). While hypoxia itself did not have an effect on heart rates, treatment with theophylline, both alone and in combination with bambuterol, increased heart rates under hypoxia (Figure 2E). None of the treatments altered plasma $\mathrm{K}^{+}$, compared to controls. Hypoxia significantly reduced plasma $\mathrm{K}^{+}$stores in all treatment groups and controls (time point \#1: $74 \pm 0.4, \# 2: 3.4 \pm 0.2, \# 3: 2.8 \pm 0.2, \# 4: 2.7 \pm 0.2 \mathrm{meq} / \mathrm{L}$ ) and levels did not recover after return to normoxia (Figure 2F). Hemoglobin saturation decreased in all groups with 
onset of hypoxia, but not significantly different in any single treatment group, compared with the other (Figure 2G).

\section{Clinical study population}

Of 37 candidates that responded to invitation, 26 were screened and 20 were included into the study. Of these, 19 (17 male, 2 female) subjects presented for study procedures (Table 1). Subjects were between 19 and 31 years of age, 169 to $195 \mathrm{~cm}$ tall, weighed 69.3 to $98.2 \mathrm{~kg}$, were nonsmokers and had an alcohol consumption of 0-23 units per week, with one unit equaling $250 \mathrm{~mL}$ of beer, $100 \mathrm{~mL}$ or a medium glass of wine, or $25 \mathrm{~mL}$ of spirits.

\section{Safety outcomes and adverse events}

Adverse events are listed in Table 2. The most common adverse event was low plasma $\mathrm{K}^{+}$and tremors both associated with bambuterol treatment. Although two subjects terminated early following the occurrence of adverse events, no hospitalization was necessary and no SAEs were recorded during the study. An inverted T-wave was observed for one subject, respectively, with both theophylline and bambuterol, but not with the combination. No other abnormal ECG-values were observed as part of any of the scans, pre- and post-dose.

\section{Clinical hemodynamics and blood chemistry outcomes}

Hemodynamic measurements and measurements of plasma $\mathrm{K}^{+}$concentrations in human subjects are shown in Figure 3, alongside with the respective average plasma drug concentration (Figure 3A, B). A significant drop in plasma $\mathrm{K}^{+}$concentration was found after treatment with bambuterol, alone and in combination with theophylline, whereas no significant drop in plasma $\mathrm{K}^{+}$was found after treatment with theophylline alone. The drop in plasma $\mathrm{K}^{+}$concentrations after bambuterol treatment roughly coincided with the peak terbutaline concentration in plasma after 4 hours (Figure $3 C$ ). The addition of theophylline to bambuterol did not aggravate plasma $\mathrm{K}^{+}$concentrations: side-by side comparison revealed no significantly reduced plasma $\mathrm{K}^{+}$concentration in combination-treated vs. bambuteroltreated subjects in any time point, although both were significantly lower than in theophylline- 
treated subjects at time points 6-10 (Figure 3D). Systolic blood pressures did not change in response to any treatment, and did also not differ between any of the treatments, when compared side-by side (Figure 3E, F). Diastolic blood pressures experienced a significant drop 8 hours after treatment with bambuterol alone, but neither did so with theophylline, nor with combined treatment. No differences were found in diastolic blood pressures between treatments in any of the time points (Figure 3G, H). Heart rates increased significantly approx. 3 hours after treatment with bambuterol, alone and in combination with theophylline, and remained elevated even after 24 hours, compared to baseline (Figure 3I, K). Heart rates did not increase after theophylline alone, and while both bambuterol and combination caused significantly higher heart rates compared to theophylline alone (time points 2, 4-12), they did not increase significantly with the combination, compared to bambuterol alone (Figure 3I).

\section{Pharmacokinetic evaluation and bioequivalence testing outcomes}

In human study samples, bambuterol concentrations in plasma were only sporadically found above the lower limit of quantification of $0.05 \mathrm{ng} / \mathrm{mL}$ and therefore, no pharmacokinetic analysis of bambuterol was possible. Drug plasma concentrations of the bambuterol catabolite terbutaline and theophylline, alone and in combination, are shown in Figure 4. Results of pharmacokinetic evaluations are in Table 3. When bambuterol was given alone, the geometric mean of the terbutaline $\mathrm{C}_{\max }$ and $\mathrm{AUC}_{0-\mathrm{T}}$ was $7.9 \mathrm{ng} / \mathrm{ml}$ and $107.8 \mathrm{~h}^{*} \mathrm{ng} / \mathrm{ml}$, respectively. When bambuterol was given together with theophylline, the geometric mean of terbutaline $C_{\max }$ and $A U C_{0-T}$ was $6.7 \mathrm{ng} / \mathrm{ml}$ and $85.0 \mathrm{~h} * \mathrm{ng} / \mathrm{ml}$. The $90 \% \mathrm{Cl}$ limits for the $\mathrm{C}_{\max }$ test/reference ratios were $61.1 \%$ and $100.9 \%$, and for the $\mathrm{AUC}_{0-\mathrm{T}}$ test/reference ratios $70.9 \%$ and $103.6 \%$. A two-sided T-test failed to confirm inclusion of the $90 \% \mathrm{Cl}$ within the $80-125 \%$ limit for both $\mathrm{C}_{\max }$ and $\mathrm{AUC}_{0-\mathrm{T}}$ (Table 3). The power of the test was $42.6 \%$ and $62.1 \%$, respectively.

When theophylline was given alone, the geometric mean of $C_{\max }$ and $A \cup C_{0-T}$ was $25.8 \mathrm{ng} / \mathrm{ml}$ and $407.8 \mathrm{~h} * \mathrm{ng} / \mathrm{ml}$, respectively. When theophylline was given together with bambuterol, the geometric mean of $C_{\max }$ and $A U C_{0-\mathrm{T}}$ was $24.3 \mathrm{ng} / \mathrm{ml}$ and $360.9 \mathrm{~h} * \mathrm{ng} / \mathrm{ml}$, respectively. The $90 \% \mathrm{Cl}$ limits for the 
individual test/reference ratios $C_{\max }$ were $87.2 \%$ and $101 \%$, and for $A \cup C_{0-T} 77.1 \%$ and $95.9 \%$. For $\mathrm{AUC}_{0-\mathrm{T}}$, the two-sided T-test failed to confirm inclusion of the $90 \% \mathrm{Cl}$ limits within the $80-125 \%$ acceptance interval, whereas in case of $C_{\max }$, the $90 \% \mathrm{Cl}$ limits were confined within the $80-125 \%$ interval. The power of the test was $95.6 \%$ and $99.8 \%$, respectively.

\section{Discussion}

The main findings are that theophylline, bambuterol, and their combination, all improve exercise performance in rats under hypobaric hypoxia and that the combination of Theo-Dur (300mg) and bambuterol $(20 \mathrm{mg})$ is relatively safe in normoxic, healthy human volunteers, with no serious AES recorded. The AEs that were noted consisted mainly of low plasma $\mathrm{K}^{+}$and tremor following bambuterol treatment. Bambuterol caused an increase in heart rate that was present when given alone or in combination with Theo-Dur and persisted $24 \mathrm{~h}$ after dosing. Drug interaction was present, but low.

Theophylline is a pleiotropic drug which, besides its long-term use to treat severe asthma, has potential value to improve health and endurance in hypoxemic individuals: although not known for any performance-enhancing effects at sea-level, theophylline, if combined with a carbonic anhydrase inhibitor, improves exercise performance capacity in hypoxemic human subjects (Scalzo et al. 2015). If combined with an endothelin-blocking vasodilator, theophylline increases hypoxic exercise performance in rats, while the single compounds are ineffective, or far less efficient (Radiloff et al. 2012). However, theophylline reportedly challenges plasma $\mathrm{K}^{+}$stores (Crane et al. 1987), although we did not observe this effect in human subjects. Since hypoxemia itself aggravates $\mathrm{K}^{+}$plasma stores (Malhotra et al. 1975), which we have confirmed in rats, this parameter will require careful monitoring when theophylline is tested in hypoxemic humans.

The mechanism of action of theophylline potentially relies on its two major effects on the cardiovascular system: nonspecific phosphodiesterase inhibition produces bronchial and vascular smooth muscle dilatation, and adenosine $\mathrm{A} 1$ and $\mathrm{A} 2$ receptor antagonism is responsible for its 
vasoconstrictive effect (Barnes 2013; Casey et al. 2009). The latter mechanism is of particular importance: adenosine is a hypoxia-triggered vasodilatory tissue factor that serves to direct local blood flow to the site of demand (Marshall 2000). Under acute hypoxemia, excessive dilatation of peripheral resistance vessels, partially caused by adenosine, causes initial systemic hypotension which is then quickly compensated for by increased cardiac output (Naeije 2010). This cardiac effect of theophylline, which is likely present in humans too, is known to be specific to hypoxia and is rooted in the inhibition of sympathetic outflow by adenosine. Adenosine receptor inhibition thus increases sympathetic nerve activity and adrenaline levels in the blood under hypoxia (Marshall 2000). Theophylline might therefore partially relieve the heart from its compensatory duty, by reducing or preventing hypoxemia-induced, adenosine-triggered vasodilatation (Radiloff et al. 2012).

Bambuterol, an orally available, long-acting $\beta 2$ - adrenergic receptor agonist (Dorfmuller et al. 2003), was chosen as a pairing vasodilator, to improve oxygen availability by increasing capillary conductivity in skeletal muscle and other tissues. Bambuterol is a carbamate prodrug of the $\beta 2 A R$ agonist terbutaline, and the kinetics of its conversion permits for single daily oral dosing (D'Alonzo et al. 1995; Sitar et al. 1993).

Typical adverse effects of bambuterol include tachycardia, palpitations, hypokalemia, and associated tremor (Cazzola et al. 2013). Pharmacokinetic parameters of terbutaline are the expected range, compared to previous work: In previous studies, the mean plasma half-life for bambuterol was 12 and 14 h, individually ranging over 20 hours (Bang et al. 1998; Nyberg et al. 1998), which agrees well with our finding of $15.3 \mathrm{~h}$. Bambuterol clearly challenged plasma $\mathrm{K}^{+}$stores, with average values undercutting $3.5 \mathrm{mM}$ and the lowest value being $2.9 \mathrm{mM}$. While no effect was found on systolic blood pressure, the slight decrease in diastolic blood pressure observed with bambuterol alone is best explained by decreased vascular resistance following vasodilatation. The increase in heart rates with bambuterol present is a known side effect of $\beta 2 A R$ agonists and can be partially assigned to the decreased $\mathrm{K}^{+}$plasma concentration. 
As beta-adrenergic stimulation is almost exclusively linked to vasodilatation, such effect in the lung and the periphery is most likely part of the efficacy of bambuterol that we have seen in rats and that we would also expect in humans (Maggiorini 2010). Although bambuterol increases heart rates in human subjects by approximately 10 beats per minute 3 hours after ingestion, an effect that was reported before in humans (D'Alonzo et al. 1995), it is interesting that we did not observe this in rats in our study at given dose. With systolic pressure remaining relatively stable in humans, such rise in cardiac activity could translate into increased perfusion pressure to tissue, potentially resulting in increased rates of oxygen and nutrient transport to skeletal muscle, with appropriate peripheral vasodilatation in place. Net vasodilatation also probably underlies the hypotensive effect of bambuterol observed in rats under hypoxia, while cardiac stimulation was absent (Figure 2D, CE). Because $\beta 2$ - adrenergic vasodilatation plays a dominant role in maintaining normal tissue blood flow (Blauw et al. 1995; Marshall 2000; Weisbrod et al. 2001), the stimulation of $\beta 2$ adrenoceptors could indeed improve oxygen transport to tissues by acting locally: terbutaline, the active metabolite of bambuterol, has reported abilities to restore the contractile force of isolated hypoxic skeletal muscle in vitro, highlighting its potential efficacy in hypoxic peripheral tissues in vivo (McDonald et al. 2015). Whether such increased transport to peripheral tissue after bambuterol treatment is actually happening in hypoxic/ hypoxemic humans will be the subject of future studies.

Combination of theophylline and bambuterol: Initial data on the combination of theophylline and bambuterol were acquired in awake rats, to better understand the cardiovascular effect of this drug combination and to identify any potential unexpected acute toxicity. The run-to-fatigue trials demonstrated that the combination of theophylline increased hypoxic exercise endurance in the animals over the single compounds, suggesting the absence of immediate negative health effects and indicating potential efficacy of the combination. The drug combination also had no detrimental effects on the mean arterial blood pressure and heart rates of the animals. It is interesting that hypoxia decreased mean arterial pressure in all treatment groups, which has only been reported in anesthetized, but not in awake rats (Duong 2007; Gao et al. 2001). This might be partially connected 


\section{Canadian Journal of Physiology and Pharmacology}

to the absence of a hypoxia-induced augmentation of heart rates (except in theophylline-treated rats), which would be part of the normal response to hypoxemic peripheral vasodilation (Bartsch et al. 2007). Also, the combination did not challenge plasma $\mathrm{K}^{+}$pools beyond the single compounds. The observed overall decrease in plasma $\mathrm{K}^{+}$is a known consequence of hypoxia (Vats et al. 2001). The absence of drug (in particular bambuterol) effects on plasma $\mathrm{K}^{+}$in rats could have various reasons, among them the possibility that the drug dose in rats was smaller than the corresponding dose given to humans. Blood oxygenation $\left(\mathrm{SaO}_{2}\right)$ was not increased in any treatment group either, indicating that augmentation of blood oxygen levels was not the mechanism by which hypoxic exercise endurance was improved in these animals. In summary, the data acquired in rats provided strong motivation to move forward with testing the combination of theophylline and bambuterol in humans.

None of the human subjects dosed with the combination of theophylline and bambuterol experienced adverse events that led to injury and/or required subsequent hospitalization, i.e. Serious Adverse Events (SAE). The largest change in any of the AE parameters occurred when the incidents of tremor increased from 10 to 14 from single-dose bambuterol to the combined dose. None of the vital parameters, including heart rates, were exacerbated when the drugs were given together, compared to the single drug situation.

Because theophylline as a single drug did not aggravate plasma $\mathrm{K}^{+}$and because of the similarity of the plasma $\mathrm{K}^{+}$curves of bambuterol during single and combined dosing, we assume that bambuterol was the dominant factor influencing plasma $\mathrm{K}^{+}$during combined treatment in humans. In other studies, patients with theophylline intoxication that led to hypokalemia (plasma $\mathrm{K}^{+}$less than 3.5 $\mathrm{mmol} / \mathrm{L}$ ) had average theophylline concentrations of $0.331 \mathrm{mmol} / \mathrm{L}$, which more than doubles the highest average measured in our study $(24.7 \mathrm{ng} / \mathrm{ml}$ at time points 10 during theophylline single dose, eq. $0.137 \mathrm{mmol} / \mathrm{L}$ (Shannon et al. 1989). Thus, although we dosed theophylline at the higher end of the therapeutic range, blood levels of the drug were insufficient to aggravate $\mathrm{K}^{+}$stores significantly. In a previous safety study that combined inhaled salbutamol and intravenous aminophylline (a 
soluble formulation of theophylline), both drugs caused significant hypokalemic effects, along with alterations in ECG profiles, such as increased QT-interval, depressed T-wave amplitude, and decreased PR interval (Crane et al. 1987).

The known stimulatory effects of theophylline on the heart are thought to be mainly caused by its inhibitory effects on phosphodiesterases (PDE) 3 and 4 (Eschenhagen 2013). PDE inhibition will initiate at concentrations beyond $2 \mu \mathrm{g} / \mathrm{ml}$ and reach a half maximum at approximately $18 \mu \mathrm{g} / \mathrm{ml}$ (Rabe et al. 1995). Since the average $C_{\max }$ of theophylline was 24.3 and $25.8 \mu \mathrm{g} / \mathrm{ml}$ in this study, PDE inhibition was, although likely present, still insufficient to translate into increased heart rates around the plasma peak time.

Our finding that the drug combination, dosed at therapeutically relevant levels, does not negatively affect plasma $\mathrm{K}^{+}$and heart rates and does not cause arrhythmia, is important enabling information for future studies in hypoxemic subjects, although these parameters will require close monitoring.

Drug interaction: Theophylline is vulnerable to drug interaction, since it is cleared to $90 \%$ via metabolism (Upton 1991). It is not known whether terbutaline directly affects the hepatic microsomal p450 enzyme CYP1A2, which is mainly responsible for theophylline hydroxylation (Nahata 1996; Upton 1991; Z. Y. Zhang et al. 1995). Terbutaline however, the active compound of bambuterol, is mainly metabolized via sulphation, which takes place both in the liver and the intestinal wall (Pacifici et al. 1993).

We found that the clearance of theophylline is slightly decelerated in the presence of bambuterol. Our results also indicate that co-administration of theophylline and bambuterol result in lower systemic exposure and $C_{\max }$ of both terbutaline and theophylline. While no evidence of interaction has been found in a previous study involving terbutaline (Jonkman et al. 1988), such discrepancy can be explained by the fact that our study has, in comparison, produced higher plasma concentrations of terbutaline, thus its potential impact on theophylline metabolism was also higher. Pharmacokinetic parameters such as plasma half-lives of theophylline that were measured in our 
study are similar to those found previously, with Theo-Dur showing a slightly longer half-life than what was reported before (Hayashi et al. 2007; Hendeles et al. 1985; Nyberg et al. 1998).

Application of the drug combination to improve human performance during hypoxemia: In the light of our findings, we expect that the combination of theophylline and bambuterol will improve oxygen availability and exercise capacity in hypoxemic humans, through improvement of blood flow in the lung and in other tissues. However, combining these drugs in hypoxemic subjects has distinct potential risks: hypoxia itself decreases plasma $\mathrm{K}^{+}$in rats and humans, and increases heart rate and cardiac output (Bartsch et al. 2007; Malhotra et al. 1975), all of which may interfere with the effects of the drugs. In addition, hypoxemia may decrease the expression of liver enzymes, thus decreasing theophylline clearance (Li et al. 2014). In particular the potential of hypoxemia to interfere with cardiac activity and plasma $\mathrm{K}^{+}$in humans are grounds for careful dosing considerations, and for close monitoring of cardiac activity and ionic profiles when testing $\beta 2 A R$ agonists and theophylline in hypoxemic subjects. This drug combination could be efficacious in restoring health and exercise capacity under environmental hypoxia, as well as in individuals suffering from PAH and lung fibrosis. The long half-life of the components would enable dosing schedules of only once per day.

\section{Conclusions}

We demonstrate that sustained-release theophylline and bambuterol can be safely combined in human subjects, evidenced by a lack of any observed additive effects or adverse events, changes in $\mathrm{K}^{+}$stores, and alterations in cardiac function. The drugs appear to influence each other's clearance to a small extent. Yet, we believe this can be resolved after dose optimization studies. Key parameters to monitor when performing testing and dose finding of combined theophylline and $\beta 2$ adrenoceptor agonists in hypoxic/ hypoxaemic volunteers are heart rates, ECG, and plasma $\mathrm{K}^{+}$concentration. In summary, the combination of bambuterol and theophylline is a promising and potentially feasible treatment of hypoxemia-related complications and hypoxemia-induced fatigue in humans. 


\section{Acknowledgements}

This work was supported by grants from the Norwegian Armed Forces Medical Service, Institute of Aviation Medicine, the US Defense Advanced Research Projects Agency (DARPA), prime Award Number N66001-10-C-2134, and by the US Office of Naval Research, prime award number N0014-140699 (Irwin, Schroeder).

\section{Figure captions}

\section{Figure 1}

Experimental setup. A: Rat in a motorized running wheel in a hypobaric tank. B: Common experimental protocol for run-to-fatigue measurements. C: Common experimental protocol for hemodynamic measurements in awake rats. Animals were injected through an intraperitoneal catheter with the study drug(s) $(0.05 \mathrm{mg} / \mathrm{kg}$ bambuterol, $15 \mathrm{mg} / \mathrm{kg}$ theophylline, or both) or $\mathrm{pH}$ adjusted saline, while breathing normoxic air (21\% oxygen). 15 minutes post injection, oxygen was reduced to $10 \%$, and normoxia was re-instated 60 minutes after drug injection. D: Treatment schedule of the human trial.

\section{Figure 2}

Results from animal studies: A: High-dose bambuterol $(0.05 \mathrm{mg} / \mathrm{kg}$, i.p.) increases the time run to fatigue in female Sprague Dawley rats under simulated high altitude $(4267 \mathrm{~m}$, log rank test, $p<0.05$, $\mathrm{n}=24$ per group). The exercise tests were carried out in motorized wheels using pre-habituated rats (Radiloff et al. 2012). B: Theophylline alone (15 mg/kg, i.p.) increases the time run to fatigue in female Sprague Dawley rats under simulated $4267 \mathrm{~m}$ of altitude. C: The combination of theophylline and bambuterol significantly increases exercise capacity under simulated altitude ( $n=10$ per group). All statistics were done with log rank test. D-G: results from hemodynamic studies on awake rats equipped with fluid-filled catheters, in a hypoxic box. 1: baseline, 2: 15 min post i.p. injection, 3: 30 min post onset of hypoxia, 4: $15 \mathrm{~min}$ post return to normoxia. Upper panels: absolute, longitudinal 
data; lower panels: values at time points, normalized to individual baselines. Significant differences between time points or treatment groups are indicated by asterisks: $p<0.05^{*}, p<0.01^{* *}, p<0.005^{* * *}$, $p<0.001^{* * * *}$.

Figure 3

Time course of hemodynamic data after single and combined dosing. A, B: plasma concentrations of theophylline and terbutaline. C, D: plasma $\mathrm{K}^{+}$concentration. $\mathrm{E}, \mathrm{F}$ : systolic blood pressure. $\mathrm{G}, \mathrm{H}$ : diastolic blood pressure. I, K: heart rate. Error bars represent the standard deviation from the mean. Longitudinal differences from the baseline value are indicated with an asterisk $\left({ }^{*}\right)$. Statistics were done with ANOVA plus Bonferroni correction for multiple comparisons.

\section{Figure 4}

Pharmacokinetics of bambuterol (terbutaline) and theophylline, given alone and in combination with each other to human subjects. Error bars represent the standard deviation from the mean.

\section{References}

Bang, U., Nyberg, L., Rosenborg, J., and Viby-Mogensen, J. 1998. Pharmacokinetics of bambuterol in subjects homozygous for the atypical gene for plasma cholinesterase. Br. J. Clin. Pharmacol. 45(5): 479-484.

Barnes, P. J. 2013. Theophylline. Am. J. Respir. Crit. Care Med. 188(8): 901-906.

Barrett-O'Keefe, Z., Ives, S. J., Trinity, J. D., Morgan, G., Rossman, M. J., Donato, A. J., et al. 2013. Taming the "sleeping giant": the role of endothelin-1 in the regulation of skeletal muscle blood flow and arterial blood pressure during exercise. Am. J. Physiol. Heart. Circ. Physiol. 304(1): H162-169.

Bartsch, P., and Gibbs, J. S. 2007. Effect of altitude on the heart and the lungs. Circulation, 116(19): 2191-2202.

Blauw, G. J., Westendorp, R. G., Simons, M., Chang, P. C., Frolich, M., and Meinders, A. E. 1995. betaAdrenergic receptors contribute to hypoxaemia induced vasodilation in man. Br. J. Clin. Pharmacol. 40(5): 453-458.

Borysova, L., Wray, S., Eisner, D. A., and Burdyga, T. 2013. How calcium signals in myocytes and pericytes are integrated across in situ microvascular networks and control microvascular tone. Cell Calcium, 54(3): 163-174.

Casey, D. P., Madery, B. D., Pike, T. L., Eisenach, J. H., Dietz, N. M., Joyner, M. J., et al. 2009. Adenosine receptor antagonist and augmented vasodilation during hypoxic exercise. J. Appl. Physiol. (1985), 107(4): 1128-1137.

Cazzola, M., Page, C. P., Rogliani, P., and Matera, M. G. 2013. beta2-agonist therapy in lung disease. Am. J. Respir. Crit. Care. Med. 187(7): 690-696. 
Crane, J., Burgess, C. D., Graham, A. N., and Maling, T. J. 1987. Hypokalaemic and electrocardiographic effects of aminophylline and salbutamol in obstructive airways disease. N. Z. Med. J. 100(824): 309-311.

D'Alonzo, G. E., Smolensky, M. H., Feldman, S., Gnosspelius, Y., and Karlsson, K. 1995. Bambuterol in the treatment of asthma. A placebo-controlled comparison of once-daily morning vs evening administration. Chest, 107(2): 406-412.

Dayan, L., Brill, S., Hochberg, U., and Jacob, G. 2016. Is adenosine a modulator of peripheral vasoconstrictor responses? Clin. Auton. Res. 26: 141-147.

Dorfmuller, P., Perros, F., Balabanian, K., and Humbert, M. 2003. Inflammation in pulmonary arterial hypertension. Eur. Respir. J. 22(2): 358-363.

Dubrey, S., Pal, S., Singh, S., and Karagiannis, G. 2016. Digital clubbing: forms, associations and pathophysiology. Br. J. Hosp. Med. (Lond.), 77(7): 403-408.

Duong, T. Q. 2007. Cerebral blood flow and BOLD fMRI responses to hypoxia in awake and anesthetized rats. Brain Res. 1135(1): 186-194.

Eschenhagen, T. 2013. PDE4 in the human heart - major player or little helper? Br. J. Pharmacol. 169(3): 524-527.

Fromm, R. E., Jr., and Varon, J. 1994. Acute exacerbations of obstructive lung disease. What to do when immediate care is crucial. Postgrad. Med. 95(8): 101-106.

Gao, E., Kaplan, J. L., Shi, Y., Victain, M., Dalsey, W. C., and de Garavilla, L. 2001. Adenosine A1 receptor antagonist prolongs survival in the hypoxic rat. J. Cardiovasc. Pharmacol. 38(3): 384-394.

Gouyon, J. B., and Guignard, J. P. 1988. Theophylline prevents the hypoxemia-induced renal hemodynamic changes in rabbits. Kidney Int. 33(6): 1078-1083.

Hall, C. N., Reynell, C., Gesslein, B., Hamilton, N. B., Mishra, A., Sutherland, B. A., et al. 2014. Capillary pericytes regulate cerebral blood flow in health and disease. Nature, 508(7494): 55-60.

Hayashi, T., Kanbe, H., Okada, M., Kawase, I., Ikeda, Y., Onuki, Y., et al. 2007. In vitro and in vivo sustained-release characteristics of theophylline matrix tablets and novel cluster tablets. Int. J. Pharm. 341(1-2): 105-113.

Hendeles, L., Massanari, M., and Weinberger, M. 1985. Update on the pharmacodynamics and pharmacokinetics of theophylline. Chest, 88(2 Suppl): 103S-111S.

Irwin, D. C., Foreman, B., Morris, K., White, M., Sullivan, T., Jacobs, R., et al. 2008. Polymerized bovine hemoglobin decreases oxygen delivery during normoxia and acute hypoxia in the rat. Am. J. Physiol. Heart Circ. Physiol. 295(3): H1090-H1099.

Jain, S., Khera, R., Girotra, S., Badesch, D., Wang, Z., Murad, M. H., et al. 2017. Comparative Effectiveness of Pharmacological Interventions for Pulmonary Arterial Hypertension: A Systematic Review and Network Meta-Analysis. Chest, 151(1): 90-105.

Jonkman, J. H., Borgstrom, L., van der Boon, W. J., and de Noord, O. E. 1988. Theophyllineterbutaline, a steady state study on possible pharmacokinetic interactions with special reference to chronopharmacokinetic aspects. Br. J. Clin. Pharmacol. 26(3): 285-293.

Julious, S. A. 2004. Sample sizes for clinical trials with normal data. Stat. Med. 23(12): 1921-1986.

Kawano, H., Sengyoku, H., Satoh, O., Urabe, S., Koide, Y., and Yano, K. 2007. Marked improvement with sildenafil in a patient with idiopathic pulmonary arterial hypertension unresponsive to beraprost and sarpogrelate. Intern. Med. 46(12): 893-898.

Kim, K. J., Baek, I. W., Yoon, C. H., Kim, W. U., and Cho, C. S. 2015. Association of Anemic Hypoxia and Increased Pulmonary Artery Systolic Pressure in Patients With Systemic Lupus Erythematosus. Arthritis Care Res. (Hoboken), 67(12): 1702-1711.

Kwon, M. S., Woo, S. K., Kurland, D. B., Yoon, S. H., Palmer, A. F., Banerjee, U., et al. 2015. Methemoglobin is an endogenous toll-like receptor 4 ligand-relevance to subarachnoid hemorrhage. Int. J. Mol. Sci. 16(3): 5028-5046.

Kylhammar, D., and Rådegran, G. 2017. The principal pathways involved in the in vivo modulation of hypoxic pulmonary vasoconstriction, pulmonary arterial remodelling and pulmonary hypertension. Acta Physiol. (Oxf.) 219(4): 728-756. 
Leblais, V., Delannoy, E., Fresquet, F., Begueret, H., Bellance, N., Banquet, S., et al. 2008. betaadrenergic relaxation in pulmonary arteries: preservation of the endothelial nitric oxide-dependent beta2 component in pulmonary hypertension. Cardiovasc. Res. 77(1): 202-210.

Li, X., Wang, X., Li, Y., Yuan, M., Zhu, J., Su, X., et al. 2014. Effect of exposure to acute and chronic high-altitude hypoxia on the activity and expression of CYP1A2, CYP2D6, CYP2C9, CYP2C19 and NAT2 in rats. Pharmacology, 93(1-2): 76-83.

Maggiorini, M. 2010. Prevention and treatment of high-altitude pulmonary edema. Prog. Cardiovasc. Dis. 52(6): 500-506.

Malhotra, M. S., Brahmachari, H. D., Sridharan, K., Purshottam, T., Ramachandran, K., and Radhakrishnan, U. 1975. Electrolyte changes at $3500 \mathrm{~m}$ in males with and without high-altitude pulmonary edema. Aviat. Space Environ. Med. 46(4 Sec 1): 409-412.

Marshall, J. M. 2000. Adenosine and muscle vasodilatation in acute systemic hypoxia. Acta. Physiol. Scand. 168(4): 561-573.

McDonald, F. B., Skelly, J. R., and O'Halloran, K. D. 2015. The beta2 -adrenoceptor agonist terbutaline recovers rat pharyngeal dilator muscle force decline during severe hypoxia. Oral Dis. 21(1): e121-127. Murray, I. R., Baily, J. E., Chen, W. C., Dar, A., Gonzalez, Z. N., Jensen, A. R., et al. 2016. Skeletal and cardiac muscle pericytes: Functions and therapeutic potential. Pharmacol. Ther. 171: 65-74.

Naeije, R. 2010. Physiological adaptation of the cardiovascular system to high altitude. Prog. Cardiovasc. Dis. 52(6): 456-466.

Naeije, R., Huez, S., Lamotte, M., Retailleau, K., Neupane, S., Abramowicz, D., et al. 2010. Pulmonary artery pressure limits exercise capacity at high altitude. Eur. Respir. J. 36(5): 1049-1055.

Nagai, H., Kuwahira, I., Schwenke, D. O., Tsuchimochi, H., Nara, A., Inagaki, T., et al. 2014. beta2Adrenergic receptor-dependent attenuation of hypoxic pulmonary vasoconstriction prevents progression of pulmonary arterial hypertension in intermittent hypoxic rats. PLoS One, 9(10): e110693.

Nahata, M. 1996. Drug interactions with azithromycin and the macrolides: an overview. J. Antimicrob. Chemother. 37 (Suppl. C): 133-142.

Nakamura, C. T., Ng, G. Y., Paton, J. Y., Keens, T. G., Witmer, J. C., Bautista-Bolduc, D., et al. 2002. Correlation between digital clubbing and pulmonary function in cystic fibrosis. Pediatr. Pulmonol. 33(5): 332-338.

Neuhaus, A. A., Couch, Y., Sutherland, B. A., and Buchan, A. M. 2016. Novel method to study pericyte contractility and responses to ischaemia in vitro using electrical impedance. J. Cereb. Blood Flow Metab. epub 1 Jan 2016. DOI: 10.1177/0271678X16659495

Nyberg, L., Rosenborg, J., Weibull, E., Jonsson, S., Kennedy, B. M., and Nilsson, M. 1998. Pharmacokinetics of bambuterol in healthy subjects. Br. J. Clin. Pharmacol. 45(5): 471-478.

Pacifici, G. M., Eligi, M., and Giuliani, L. 1993. (+) and (-) terbutaline are sulphated at a higher rate in human intestine than in liver. Eur. J. Clin. Pharmacol. 45(5): 483-487.

Pitsiou, G. G., Chavouzis, N., Nakou, C., Boutou, A. K., Argyropoulou, P., and Stanopoulos, I. 2009. Successful up-front combination therapy in a patient with idiopathic pulmonary hypertension and patent foramen ovale: an alternative to epoprostenol therapy? J. Heart Lung Transplant. 28(6): 651653.

Rabe, K. F., Magnussen, H., and Dent, G. 1995. Theophylline and selective PDE inhibitors as bronchodilators and smooth muscle relaxants. Eur. Respir. J. 8(4): 637-642.

Radiloff, D. R., Zhao, Y., Boico, A., Wu, C., Shan, S., Palmer, G., et al. 2012. The combination of theophylline and endothelin receptor antagonism improves exercise performance of rats under simulated high altitude. J. Appl. Physiol. (1985), 113(8): 1243-1252.

Scalzo, R. L., Binns, S. E., Klochak, A. L., Giordano, G. R., Paris, H. L., Sevits, K. J., et al. 2015. Methazolamide Plus Aminophylline Abrogates Hypoxia-Mediated Endurance Exercise Impairment. High. Alt. Med. Biol, 16(4): 331-342.

Shannon, M., and Lovejoy, F. H., Jr. 1989. Hypokalemia after theophylline intoxication. The effects of acute vs chronic poisoning. Arch. Intern. Med. 149(12): 2725-2729. 
Sitar, D. S., Aoki, F. Y., Warren, C. P., Knight, A., Grossman, R. F., Alexander, M., et al. 1993. A placebo-controlled dose-finding study with bambuterol in elderly patients with asthma. Chest, 103(3): 771-776.

Upton, R. A. 1991. Pharmacokinetic interactions between theophylline and other medication (Part I). Clin. Pharmacokinet. 20(1): 66-80.

Vats, P., Singh, S. N., Kumria, M. M., Ranganathan, S., Arora, M. P., Kylhammar, C. L., et al. 2001. Effect of hypoxia on the circulating levels of essential mineral elements in rats. J. Environ. Biol. 22(4): 277-282.

Weisbrod, C. J., Minson, C. T., Joyner, M. J., and Halliwill, J. R. 2001. Effects of regional phentolamine on hypoxic vasodilatation in healthy humans. J. Physiol. (Lond.) 537(Pt 2): 613-621.

Zhang, H., Feng, L., Wan, Q. L., Hong, Y., Li, Y. M., Cheng, G. C., et al. 2015. Sleep-disordered breathing is associated with depletion of circulating endothelial progenitor cells and elevation in pulmonary arterial pressure in patients with decompensated systolic heart failure. J. Geriatr. Cardiol. 12(4): 424-430.

Zhang, Z. Y., and Kaminsky, L. S. 1995. Characterization of human cytochromes P450 involved in theophylline 8-hydroxylation. Biochem. Pharmacol. 50(2): 205-211. 
Table 1: Demographics

\begin{tabular}{|ccc|}
\hline Sex & Female & Male \\
\hline Number & 2 & 17 \\
\hline Age $(\mathrm{yrs})$ & $23.7(19-27)$ & $23.6(20-31)$ \\
\hline Height $(\mathrm{cm})$ & $175.3(169-183)$ & $181.2(171-195)$ \\
\hline Weight $(\mathrm{kg})$ & $78.7(72.4-83.4)$ & $81.4(69.3-98.2)$ \\
\hline
\end{tabular}


Table 2: Summary of adverse events

\begin{tabular}{|c|c|c|c|}
\hline & Bambuterol & Theophylline & Combination \\
\hline $\mathrm{K}^{+}<3.5 \mathrm{mM}$ & 12 & 4 & 13 \\
\hline Tremor & 10 & 0 & 14 \\
\hline Dizziness & 0 & 1 & 0 \\
\hline Palpitations & 4 & 1 & 4 \\
\hline Nausea & 3 & 1 & 2 \\
\hline Chest pain and inspirational discomfort & 1 & 0 & 1 \\
\hline Reduced appetite & 0 & 1 & 0 \\
\hline Upper respiratory tract infection & 0 & 1 & 0 \\
\hline Sleeping disturbances & 0 & 0 & 1 \\
\hline Mucosal gum bleeding & 0 & 1 & 0 \\
\hline Tachycardia & 1 & 0 & 1 \\
\hline Inverted T-wave in ECG & 1 & 1 & 0 \\
\hline Fatigue & 1 & 0 & 0 \\
\hline Extrasystole in ECG & 0 & 0 & 1 \\
\hline Headache & 0 & 1 & 0 \\
\hline Increased diuresis & 0 & 1 & 0 \\
\hline Lower extremity fasciculation & 0 & 1 & 0 \\
\hline Overall number of adverse events & 33 & 14 & 37 \\
\hline
\end{tabular}


Table 3: Pharmacokinetic results from the human trial of terbutaline and theophylline after dosing of bambuterol and theophylline alone and in combination

\begin{tabular}{|c|c|c|c|c|c|c|c|c|c|c|c|c|}
\hline \multirow[t]{2}{*}{ Parameter } & \multicolumn{3}{|c|}{$\begin{array}{c}\text { Bambuterol alone } \\
\text { (Terbutaline) }\end{array}$} & \multicolumn{3}{|c|}{$\begin{array}{c}\text { Bambuterol (Terbutaline), } \\
\text { theophylline present }\end{array}$} & \multicolumn{3}{|c|}{ Theophylline alone } & \multicolumn{3}{|c|}{$\begin{array}{c}\text { Theophylline } \\
\text { (bambuterol present) }\end{array}$} \\
\hline & Geomean & SD & $N$ & Geomean & SD & $N$ & Geomean & $\mathrm{SD}$ & $N$ & Geomean & SD & $N$ \\
\hline $1 / h$ & 0.0452 & 0.0228 & 16 & 0.0493 & 0.1223 & 16 & 0.0640 & 0.0129 & 6 & 0.0666 & 0.0048 & 3 \\
\hline$t_{1 / 2}$ & 15.3 & 14.4 & 16 & 14.1 & 22.0 & 16 & 10.8 & 2.1 & 6 & 10.4 & 0.7 & 3 \\
\hline$T_{\max }$ & 5.0 & 2.1 & 18 & 4.2 & 1.8 & 16 & 9.7 & 3.8 & 19 & 10.2 & 4.0 & 17 \\
\hline$\mu \mathrm{g} / \mathrm{mL}$ & 7.9 & 2.2 & 18 & 6.7 & 2.4 & 16 & 25.8 & 3.6 & 19 & 24.3 & 4.9 & 17 \\
\hline$T_{\text {last }}$ & 23.1 & 2.8 & 18 & 21.8 & 4.5 & 16 & 23.1 & 2.8 & 19 & 22.1 & 4.0 & 17 \\
\hline$\mu \mathrm{g} / \mathrm{mL}$ & 2.7 & 0.8 & 18 & 2.1 & 1.0 & 16 & 12.8 & 5.6 & 19 & 12.8 & 4.7 & 17 \\
\hline $\begin{array}{l}h \cdot \mathrm{ng} / \mathrm{mL}_{\text {Bam }} \\
h \cdot \mu \mathrm{g} / \mathrm{mL}_{\text {Theo }}\end{array}$ & 107.8 & 31.3 & 18 & 85.0 & 37.7 & 16 & 407.8 & 86.4 & 19 & 360.9 & 95.9 & 17 \\
\hline $\begin{array}{l}h \cdot \mathrm{ng} / \mathrm{mL}_{\text {Bam }} \\
h \cdot \mu \mathrm{g} / \mathrm{mL}_{\text {Theo }}\end{array}$ & 177.5 & 56.4 & 16 & 146.0 & 133.8 & 16 & 552.3 & 93.3 & 6 & 455.9 & 60.6 & 3 \\
\hline $\mathrm{Vz} / \mathrm{F}$ & 2491.2 & 1155.4 & 16 & 2816.2 & 1319.6 & 16 & 8.5 & 1.9 & 6 & 9.9 & 0.7 & 3 \\
\hline $\mathrm{mL} / \mathrm{min}$ & 1878.3 & 467.4 & 16 & 2314.3 & 3815.5 & 16 & 9.1 & 1.9 & 6 & 11.0 & 1.5 & 3 \\
\hline $\mathrm{MRT}_{\text {last }}$ & 10.1 & 1.1 & 18 & 9.6 & 2.0 & 16 & 11.6 & 1.5 & 19 & 11.5 & 2.0 & 17 \\
\hline
\end{tabular}


A

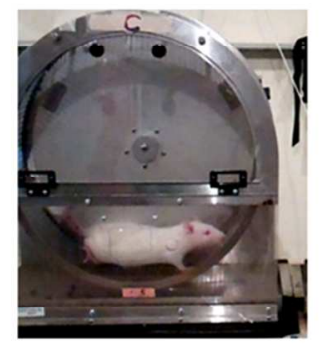

B

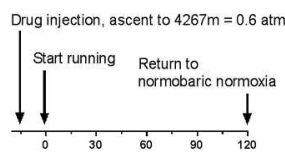

C

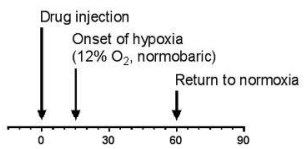

D

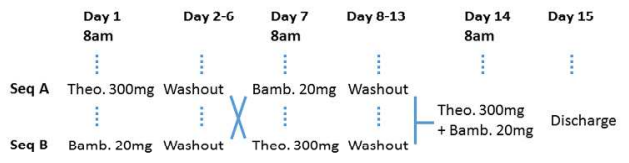

Experimental setup. A: Rat in a motorized running wheel in a hypobaric tank. B: Common experimental protocol for run-to-fatigue measurements. C: Common experimental protocol for hemodynamic measurements in awake rats. Animals were injected through an intraperitoneal catheter with the study drug(s) $(0.05 \mathrm{mg} / \mathrm{kg}$ bambuterol, $15 \mathrm{mg} / \mathrm{kg}$ theophylline, or both) or $\mathrm{pH}$-adjusted saline, while breathing normoxic air ( $21 \%$ oxygen). 15 minutes post injection, oxygen was reduced to $10 \%$, and normoxia was reinstated 60 minutes after drug injection. D: Treatment schedule of the human trial.

$$
500 \times 400 \mathrm{~mm}(300 \times 300 \text { DPI })
$$



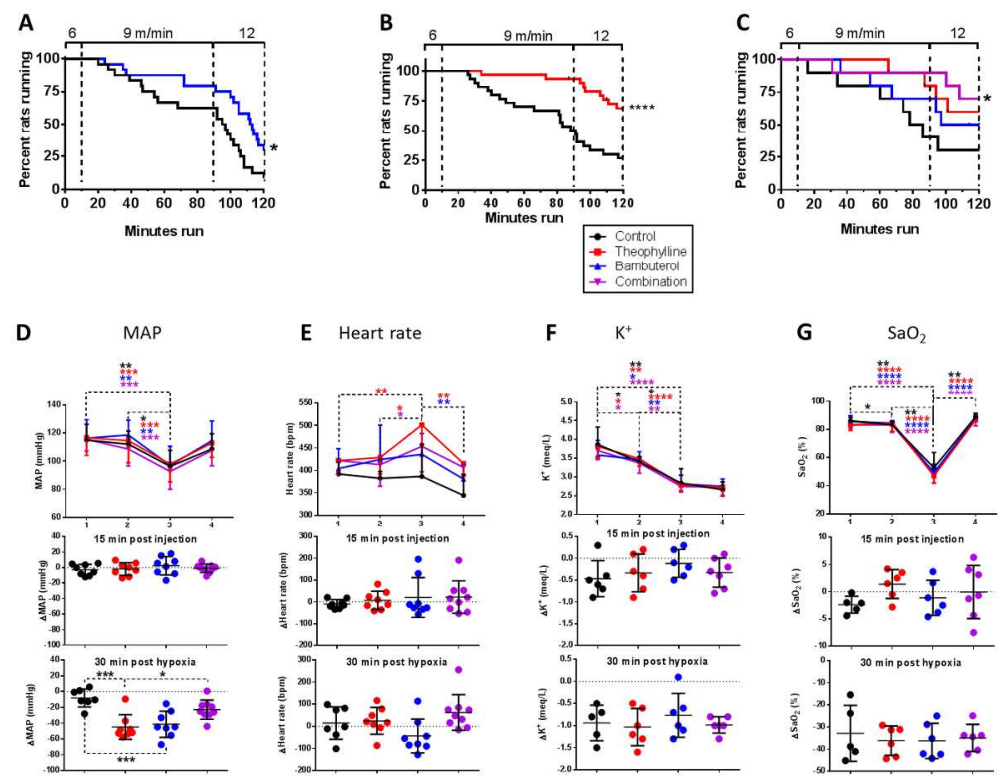

Results from animal studies: A: High-dose bambuterol $(0.05 \mathrm{mg} / \mathrm{kg}, \mathrm{i} . \mathrm{p}$.) increases the time run to fatigue in female Sprague Dawley rats under simulated high altitude $(4267 \mathrm{~m}$, log rank test, $\mathrm{p}<0.05, \mathrm{n}=24$ per group). The exercise tests were carried out in motorized wheels using pre-habituated rats (Radiloff et al. 2012). B: Theophylline alone $(15 \mathrm{mg} / \mathrm{kg}$, i.p.) increases the time run to fatigue in female Sprague Dawley rats under simulated $4267 \mathrm{~m}$ of altitude. C: The combination of theophylline and bambuterol significantly increases exercise capacity under simulated altitude ( $n=10$ per group). All statistics were done with log rank test. $D-$ $\mathrm{G}$ : results from hemodynamic studies on awake rats equipped with fluid-filled catheters, in a hypoxic box. 1: baseline, 2: 15 min post i.p. injection, 3: 30 min post onset of hypoxia, 4: 15 min post return to normoxia. Upper panels: absolute, longitudinal data; lower panels: values at time points, normalized to individual baselines. Significant differences between time points or treatment groups are indicated by asterisks:

$$
\mathrm{p}<0.05^{*}, \mathrm{p}<0.01 * *, \mathrm{p}<0.005^{* * *}, \mathrm{p}<0.001 * * * * \text {. }
$$

$500 \times 400 \mathrm{~mm}(300 \times 300$ DPI $)$ 

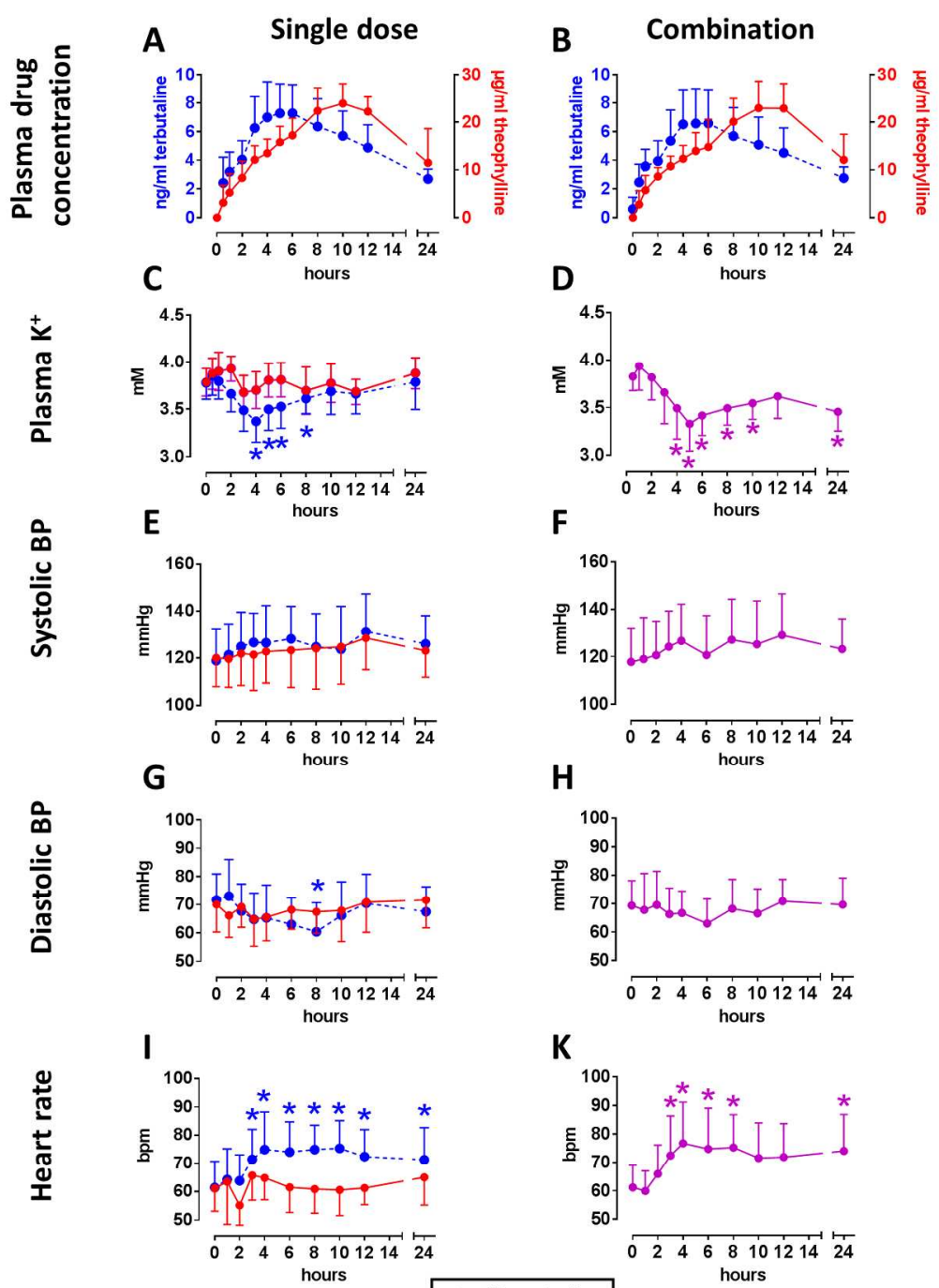

K

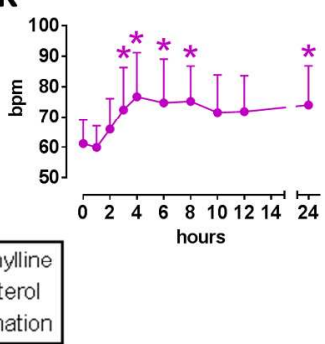

Time course of hemodynamic data after single and combined dosing. A, B: plasma concentrations of theophylline and terbutaline. C, D: plasma K+ concentration. E, F: systolic blood pressure. G, H: diastolic blood pressure. I, K: heart rate. Error bars represent the standard deviation from the mean. Longitudinal differences from the baseline value are indicated with an asterisk $(*)$. Statistics were done with ANOVA plus Bonferroni correction for multiple comparisons.

$500 \times 650 \mathrm{~mm}(250 \times 250 \mathrm{DPI})$ 

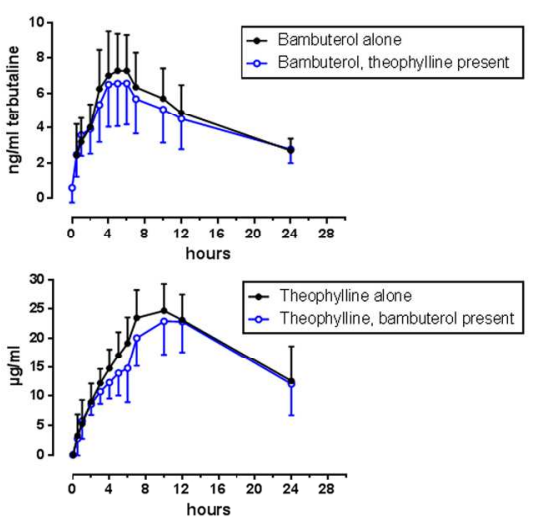

Pharmacokinetics of bambuterol (terbutaline) and theophylline, given alone and in combination with each other to human subjects. Error bars represent the standard deviation from the mean.

$190 \times 107 \mathrm{~mm}(300 \times 300 \mathrm{DPI})$ 